\title{
Mata Uang Logam Cina: Salah Satu Sarana Rekonstruksi Sejarah
}

\section{Yuniarso K Adi}

Keywords: Chinese coins, currency, trade, numismatic.

\section{How to Cite:}

Adi, Y. K. Mata Uang Logam Cina: Salah Satu Sarana Rekonstruksi Sejarah. Berkala Arkeologi, 14(2), 173-181. https:// doi.org/10.30883/jba.v14i2.718

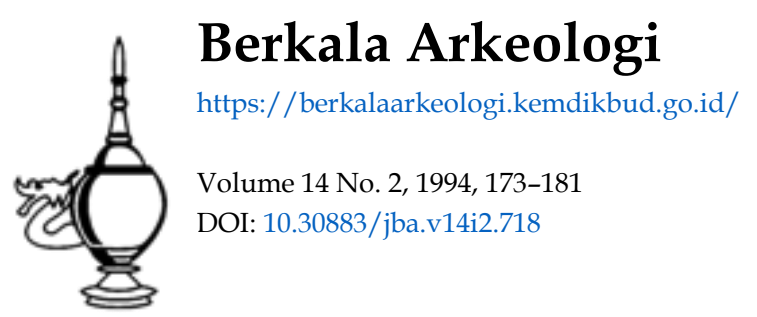

\section{cc) (†) (2)}

This work is licensed under a Creative Commons Attribution-NonCommercial-ShareAlike 4.0 International License. 


\title{
MATA UANG LOGAM CINA SALAH SATU SARANA REKONSTRUKSI SEJARAH
}

\author{
Yuniarso K Adi \\ (Museum Negeri Provinsi Jateng "Ronggowarsito")
}

।

Mata uang merupakan salah satu sarana kegiatan perdagangan dan perekonomian yang menentukan. Hal tersebut terjadi sejak kehidupan masyarakat mulai mengenal perdagangan dan harga. Mata uang menurut Ensiklopedi Nasional Indonesia adalah alat tukar atau alat bayar yang diterıma secara umum, memiliki satuan nilai standar dan daya beli terhadap barang dan jasa

Alat tukar dikenal masyarakat sejak jaman prasejarah dalam berbagai macam bentuk dan standart nilai. Ada yang berbentuk gigi binatang buruan, manik-manik, batu-batuan, kulit kerang, dan lain sebagainya (Magdalena L, 1991:2-3). Masyarakat pertama yang sudah mengenal dan mempergunakan mata uang sebagai alat tukar dan standart nilai secara resmi adalah Mesir, Yunanı, dan Cina.

Kegiatan perdagangan Cina mulai merambah Asia Tenggara sejak abad II SM (Bambang, S., 1990:13). Namun bukti tertulis tentang hubungan Cina dengan Indonesia pada abad II SM belum diperoleh. Bukti-bukti tentang kehadiran Cina di wilayah AsiaTenggara pertama kali secara tertulis baru dapat disajikan oleh dua orang pendeta Buddha, yaitu Fa-Hsien dan Gunavarman. Fa Hsien melakukan perjalanan mulai tahun $413 \mathrm{M}$, sedangkan Gunavarman melakukan perjalanan kurang lebih antara tahun 424-453 M. Data lain yang memuat tentang aktivitas perdagangan antara masyarakat Asia Tenggara dengan Cina terdapat dalam sebuah berita Tambo dinasti Chı Selatan (479-502 M) yang menerangkan tentang adanya kegiatan perdagangan antara Cina dengan kapal K'un-lun, menurut masyarakat Cina K'un-lun adalah sebutan untuk orang-orang dari Asia Tenggara. Namun apakah kegiatan perdagangan tersebut diatas juga termasuk bangsa Indonesia, belum ada data yang menyebutkannya.

Darı data tertulis yang menguraikan kegratan perdagangan bangsa Cina dengan Asia Tenggara, belum ada data yang menyebutkan secara pasti tentang wilayah Indonesia yang pernah didatangi oleh bangsa Cina. Upaya yang dilakukan oleh para ahli sejarah maupun arkeolog hıngga sekarang ini baru sampai tahap interpretasi berdasarkan toponim, belum sampai pada interpretasi yang didasarkan pada data yang akurat. Masalah yang sangat mendasar berkaitan dengan interpretasi sumber-sumber data yang digunakan (Bambang, S.,1991:21). Selain itu tidak ada temuan artefaktual yang mendukung, serta kesulitan bahasa, karena penggunaan bahasa masyarakat Cina dengan suku-suku bangsa di Indonesia berbeda.
Buktı artefaktual yang dapat membantu mengungkapkan kegiatan perdagangan Cina di indonesia salah satunya adalah mata uang logam $\mathrm{Ci}$ na. Namun sejauh ini ada beberapa segi keuntungan dan kelemahan dalam mempergunakan mata uang logam sebagai salah satu sarana mengungkapkan sejarah. Keuntungannya adalah.

1. Mata uang banyak diketemukan di beberapa wilayah di Indonesia

2. Dalam mata uang terdapat inskripsi yang menyebutkan tentang data tokoh maupun data tekstual lainnya.

3. Dalam teori rekonstruksi sejarah data inskrıpsı (tekstual) merupakan data primer

4. Populasi peredaran mata uang logam memudahkan kompilasi data untuk memperoleh satu kesamaan asal tahun dan insriksı yang tertulis.

Sedangkan kelemahannya

1. Mata uang logam masa berlakunya kadangkadang melewati batas tahun berkuasanya sang penguasa yang mencetaknya

2. Penguasaan bahasa serta huruf Cina para peneliti masih minim.

3. Mobilitas yang tinggi mata uang logam (kehadiran mata uang di suatu wilayah tidak disertai masyarakat pencetak maupun penggunanya).

4. Terjadinya kemungkinan antara kehadiran masyarakat pencetaknya dengan mata uangnya lebih dahulu hadir masyarakatnya. Sedangkan mata uangnya baru hadir sekian tahun kemudian atau sebaliknya

5. Masa berlakunya kadang-kadang lebih panjang (lama) dibandingkan masa kekuasaan pencetaknya, sehingga sang pencetak (penguasa yang menerbitkannya) sudah tidak berkuasa, namun mata uangnya masih beredar luas

\section{॥}

Mata uang logam Cina yang diketemukan di Propinsi Jawa Tengah sangat banyak. Temuan mata logam Cina yang tersimpan di Museum Negeri Propinsi Jawa Tengah "Ronggowarsito" dalam jumlah banyak dengan berat keseluruhan $\pm 50 \mathrm{~kg}$ berasal dari berbagai daerah. Menarik perhatian dari beberapa temuan mata uang iogam Cina adalah diketemukannya mata uang logam dari Jepang dengan bentuk, bahan, uku-ran, serta tempat temuan yang sama.

Persebaran temuan mata uang logam Cina yang tersimpan antara lain berasal dari Kabupaten Pati, Kudus, Batang, Kendal, Tegal, Cilacap. 
Temanggung. Purworejo, dan Blora. Secara geografis asal temuan tertinggi berada di wilayah pantai (pesısir) dengan 7 (tujuh) wilayah, Pati, Kudus, Batang, Kendal. Tegal, Cilacap, dan Blora Sedangkan temuan yang berasal dari pedalaman adalah Purworejo dan Temanggung.

Dari beberapa wilayah tersebut di atas, Museum Negeri Prop. Jateng sudah melakukan penelitian ınskrıpsı mata uang logam Cina darı Kab. Patı dan Kab. Kudus. Temuan dari Kab. Pati berasal dari Dukuh Tulis Desa Kedalon Kecamatan Batangan yang ditemukan pada tanggal 6 Maret 1986 berjumlah 713 kepıng mata uang. Dari 713 keping mata uang dapat dirinci sebagai berikut

467 kepıng dapat terbaca serta diketahui asal dinastinya

134 kepıng tidak diketahuı dinasti serta tahun terbit.

104 kepıng tidak dapat terbaca karena aus.

8 keping belum dapat terbaca karena karakter tulisannya berbeda dengan tulisan yang terdapat pada mata uang Cina lainnya.

Temuan dari Kabupaten Kudus berasal dari Dukuh Ngemplak Desa Gondosari Kecamatan Gebog. Jumlah seluruhnya ada 80 keping dengan perincian sebagai berikut.

- 46 kepıng dapat terbaca serta diketahui asal dinastinya.

- 10 kepıng dapat terbaca namun tidak dapat diketahui asal dinasti serta tahun terbit

- 21 kepıng tidak dapat terbaca karena aus

3 kepıng rusak (hancur).

Satu hai yang menarik dari temuan tersebut adaiah bahwa kedua temuan ditemukan dalam jenıs wadah yang sama yaitu tempayan yang dıperkırakan berasal darı dinastı Tang

Ciri--cirı mata uang logam Cina yang ditemukan bulat dengan bagian tengahnya berlubang persegi empat, berbahan perunggu, $\oslash 2,3$ $\mathrm{cm}$ tebal $0.15 \mathrm{~cm}$, jarak lubang $9 \mathrm{~mm}$, dan lebar lupang persegi $7 \mathrm{~mm}$, berat antara 3.3.5 gram Pada salah satu sisinya bertuliskan nama dinastı yang mengeluarkan mata uang tersebut, dan sisi laın umumnya polos. Tulisan yang terdapat pada mata uang logam bıasanya terdiri dari 4 (empat) huruf mengelilingi lubang persegi dengan sistem pembacaan se-arah Jarum jam

Rentang waktu dinasti pembuat mata uang logam temuan dari Pati adalah darı dınastı Tang masa kekaısaran Kaıyuan (713 M) sampai dinastI Mingmasa kekaisaranYongla (1404-1424 M) yaitu \pm 711 tahun. Secara berurutan dapat disebut dinastınya yaitu Tang (618-859 M), Song Utara (960-1126 M), Daghı (kaisar Jepang) (1126$1131 \mathrm{M})$, Song Selatan (1127-1260), Yuan (1261 -1267 M), dan Ming (1368-1644 M). Adapun Jumlah temuan masıng-masing dinasti adalah

Uınastı Tang

Dınastı Song Utara

49 keping

305 kepıng
Dinasti Daghi (Jepang)

Dinasti Song Selatan

Dinasti Ming

Inskripsi Xianfu

1 keping

11 keping

142 keping

22 kepıng

Inskripsı Huang Song Tong Bao 112 keping

Temuan mata uang yang berasal darı Kudus rentang waktu dinasti serta kekaisarannya hanya 487 tahun dimulai masa kekaisaran Kaı. yuan (713 M) hingga dinasti Song Selatan masa kekaısaran Qingyuan (1195-1200 M). Secara terinci dapat dibaca antara lain:

Dinasti Tang

Dinastı Song Utara

Dinasti Song Selatan

19 kepıng

27 keping

Inskripsi Xianfu

3 keping

Inskripsi Huang Song Tong Bao $\quad 5$ keping

Inskripsi Da Song Yuan Bao

5 keping

5 kepıng

Temuan dari Kudus ini tıdak terdapat mata uang dinasti Yuan, Ming, dan Daghı (kaısar Jepang). Secara lengkap kronologı mata uang temuan dua daerah dapat dilıhat tabel dibawah

III

Paparan data di atas menunjukkan adanya kronologi kaisar yang cukup urut dan lengkap Meskıpun antara temuan Patı dengan Kudus be:beda kronologis dinastı pembuatnya tetapı darı segı konteks temuan penyertanya dapat diseja jarkan. Selaın itu dari data di atas dapat diketa hui, setiap pergantian kaisar menerbitkan mata uang baru. Sehingga timbul pertanyaan apakan usıa peredaran mata uang Cina itu hanya sam. pal akhir kekuasaan dinastı pencetaknya? Ke mungkinan peredaran mata uang logam a indonesia bersamaan dengan berkuasanya pencetak mata uang yang bersangkutan

Hal menarik lainnya dapat dilihat dar: per. bandıngan antara temuan Patı dengan temuan Kudus

Pertama, temuan darı Patı, antara masa kaisa Zhihe (1054-1055) sampal kaısar Zhipıng (1064-1067) tidak terbit mata uang bari: Namun darı temuan Kudus ditemukan ma-ta uang yang terbit antara tahun 1056-1063 dar dinasti Xiyou. Dengan demikıan me-nutur kekosongan terbit mata uang tahun 1055-106: yang tidak ditemukan pada kronoiog penguasa darı temuan Patı

Kedua, temuan Patı darı dinasti Song Selatar antara kaısar Xi (1174-1189) sampar kar-sar Qingyuan (1195-1200) ada kesenjangan wak tu 1189-1195 tidak terbit mata uang baru Namun temuan darı Kudus menutup kekosongan tersebut dengan temuan mata uang Shaoxı (1190-1192) yang berkuasa sebelum kaisar Qingyuan

Kedua hal tersebut diatas menunjukkan satu buktı, bahwa kesınambungan penerbıtär 
mata uang setiap pergantian kaisar adalah adanya terbitan mata uang kaisar Jepang yaitu kaisar Daghi (1126-1131) yang mengisi kesenjangan dan kekosongan terbit mata uang baru antara dinasti Song Utara yaitu kaisar Yihe (1119-il25) dengan kaisar $X_{i}$ (1174-1260) dari dinasti Song Selatan. Meskipun yang menerbitkan mata uang dari kaisar Jepang namun bahan, berat, ukuran serta bentuknya sama dengan mata uang yang berasal dari kaisar Cina. Secara sepintas, jika tidak dibaca inskripsinya maka kita tidak akan dapat membedakan antara mata uang terbitan Cina dengan mata uang terbitan Jepang. Hal yang menjadikan pertanyaan adalah, apakah ada upaya pemberlakuan secara umum dari nilai mata uang yang beredar pada masa itu?

Jumlah temuan yang cukup banyak (temuan Pati 713 keping dan temuan Kudus 80 kepıng) periu dicermati, karena ada beberapa alasan yang menyebabkan peredaran mata uang Cina di Indonesia begitu banyak. Jika dikaitkan dengan teori ekonomi sekarang yaitu untuk membuat situasi ekonomi itu tetap stabil maka jumlah uang yang beredar dengan tingginya permintaan masyarakat akan uang tersebut harus sebanding agar tidak menimbulkan inflasi maupun sebaliknya.

Dari inskripsi yang dapat dibaca pada mata uang itu maka dapat diketahui penguasa yang menerbitkannya. Selanjutnya dari nama penguasa yang menerbitkannya diperoleh angka tahun masa berkuasanya Sedangkan data yang diperoleh dari Pati dan Kudus, nampak bahwa angka tahun tersebut cukup urut dan lengkap. Apakah hal ini tidak dapat dipergunakan sebagai salah satu sarana merekonstruksi tentang kehadiran Cina di Indonesia ?. Angka tahun yang diperoleh dari mata uang logam dapat dikaitkan dengan berita-berita Cina yang selama ini menjadi data utama dalam membuktikan kehadiran Cina di Indonesia. Sehingga akan diperoleh kesamaan angka tahun. Kesamaan angka tahun tersebut kemudian dicocokkan dalam berita Cina untuk mengetahui nama-nama wilayah Indonesia. Selaın itu bukti adanya kegiatan perdagangan antara Cina dengan Indonesis: didukung dengan temuan berupa mata uang.

Terlepas dari permasalahan rekonstruksi sejarah, timbul pertanyaan seberapa pentingkah keberadaan Indonesia terhadap Cina dalam dunia perdagangan sehingga dirasa perlu untuk menyebarkan uang dalam jumlah banyak dan kurun waktu yang panjang. Hal ini menggelitik kita untuk meneliti lebih jauh dan lebih dalam kegiatan perdagangan yang dilakukan antara Cina dengan Indonesia sebagai upaya mengungkap sejarah perkembangan ekonomi Indonesia.
IV

Dari paparan data di atas dapat ditarik beberapa hal berikut

1. Dapatkah data-data inskripsi mata uang logam Cina dijadikan salah satu data pendukung dalam merekonstruksi teori hubungan antar masyarakat Cina dengan masyarakat Indonesia. Sebab hingga sekarang ini inskripsı yang menyebutkan secara pasti kapan dan dımana bangsa Cina pernah datang ke Indonesia belum dapat tersajikan. Sedangkan data inskripsi yang ada hanyalah mata uang logam Cina. Interpretasi data sejarah dapat terdukung dan terbukti karena adanya data-data primer dari sumber tertulis. Apakah mata uang logam juga dapat dimasukkan sebagai sumber data tertulis?

2. Adanya standart ukuran, berat: bahan, seita bentuk mata uang logam yang berlaku dalam kurun waktu cukup panjang \pm 711 tahun menunjukkan adanya stabilitas nilai uang yang berlaku. Stabilitas nilai uang tidak akan terjadi tanpa ditunjang adanya stabilitas ekonomi, politik, budaya, dan sosıal Dengan stabilnya nilai uang yang terjadi dalam kurun waktu cukup panjang tersebut, maka dapat ditarık kesımpulan, bahwa gejolak ekonomi yang mungkın terjadi sejak dinasti Tang (abad 78) hingga dinasti Ming (abad 16) tidak begitu berpengaruh terhadap nilai uang yang berlaku (inflası, devaluasi, dsb). Pada masa modern sekarang ini perubahan nilai tukar uang dapat bergeser hanya dalam hitungan waktu menit saja. Dengan stabilnya situasi ekonomi maka nilai uang yang ada dapat diterima kaisar-kaisar yang berkuasa dalam kurun waktu tersebut.

3. Kendala yang paling utama dalam melakukan interpretasi adalah kurang luasnya penguasaan huruf-huruf Cina, sehingga mempengaruhi tingkat akurasi dan ketajaman analisa interpretasi sejarah. Hal ini menjadi tantangan yang perlu dipertimbangkan di masa yang akan datang

Kajian inskripsi mata uang logam Cina adaiah salah satu upaya untuk memberikan satu kontribusi penyediaan data analisa baru bagı Intrepretasi data sejarah dengan harapan dapat dipergunakan untuk membantu merekonstruksi sejarah. Hal ini perlu dilakukan karena hingga sekarang, data tertulis yang telah disajikan dan diperoleh oleh para ahli untuk menginterpretasikan kegiatan hubungan dagang antara Cina dengan Indonesia pada masa-masa awal lebih banyak didasarkan pada berita-berita Cina. sehingga baru sampai pada tahap studi toponim saja. Sedang. kan temuan artefaktual berupa data tertulis belum begitu lengkap. 
Kajian inskripsi mata uang logam Cina dilakukan atas bantuan dari Dennis Lombard dan Claudine Salmon peneliti budaya Cina dari Perancis yang mengunjungi Museum Neg. Prop. Jateng pada tahun 1992. Kedua penelitia tersebut membantu membaca inskripsi yang tertera pada mata uang logam Cina. Untuk pemastian analisa serta pembacaan ulang (Cross check) dibantu Yang Hao arkeolog dari Museum Negeri Guangdong (ahli nekara) yang datang di museum pada tahun 1993

\section{KEPUSTAKAAN}

Groeneveldt, WP, 1960, Historical Notes on Indonesia and Malaya Compiled from Chinese Sources.Jakarta.

Hall, D.G.E, 1968, A History of South-East Asia London etc.:Mac Millan; New York:St Martin's Press, Third Edition

Koentjaraningrat, 1981, Beberapa Pokok Antropologi Sosial. Jakarta, PT Dian Rakyat

Leo Suryadinata, 1988, Kebudayaan Minoritas Tionghoa di Indonesia Jakarta:PT Gramedia.

Leur,JC. van, 1955, Indonesian Trade and Society Bandung:The hague: $W$. van Hoeve

Marwah Djoened P \& Nugroho N, 1990, Sejarah Nasional Indonesia II. Jakarta, PN Balai Pustaka, Edisi ke 4.

Taufik Abdullah, 1988, Agama, Etos Kerja \& Perkembangan Ekonomi Jakarta:LP3E5

T.Ibrahim Alfian,dkk, 1987, Dari Babad dan Hikayat sampai Sejarah krittis. Yogyakarta, Gadjjah Mada University Press.

1991,Ensiklopedi Nasional Indonesia 4,7,17, Jakarta:PT. Cipta Adi Pustaka

1891, Ensiklopedi Umum, Yogyakarta: Kanisius.
MATA UANG LOGAM CINA:

- Nama penguasa pembuatnya

- Tahun berkuasa

- Tempat temuannya

-Macam tahun terbit mata uang

perkembangan mata uang Cina yang beredar di Indonesia

\section{MANFAAT YANG DIPEROLEH:}

- Penguasa-penguasa Cina yang pernah berhubungan dengan Indonesia

- Kepastian tempat kegiatan dagang antara

Cina dengan Indonesia

- Tempat datangnya Bangsa Cina di Indonesia (?)

- Intensitas hubungan dan kegiatan dagangnya

- Perkembangan ekonomi Cina yang terjadi di Indonesia. 
TEMOAN MATA UANG KABUPATEN PATI

\begin{tabular}{|c|c|c|c|c|}
\hline No & Dinast & Tahun & Inskripsi & Jœl keping \\
\hline \multicolumn{2}{|c|}{ DINASTI- TANG } & $618-709$ & $\sqrt{5}$ & 49 \\
\hline 1. & Kasyuan & $713-741$ & 陵 $\bar{\jmath}$ & 48 \\
\hline 2. & Daghong & $847-859$ & 大 本 & 1 \\
\hline \multicolumn{2}{|c|}{ DINASTI SONG UTARA } & $960-1126$ & 必实 & 305 \\
\hline 1. & Zhidao & $995-997$ & 王 5 章 & 1 \\
\hline 2 . & Xlanping & $998-1003$ & $5 \cdot x$ 平 & 11 \\
\hline 3. & Jingde & $1006-1017$ & $\frac{9}{2}$ & 18 \\
\hline 4. & $\operatorname{Ttan} x 1$ & $1017-1021$ & हुछ्ध & 14 \\
\hline 5. & Taiplng & $1021-1031$ & 太 $\pi$ & 3 \\
\hline 6. & Tiansheng & $1023-1032$ & 不县 & 29 \\
\hline 7. & Mingdao & $1032-1033$ & 明素 & 15 \\
\hline 8. & Jingyou & $1034-1037$ & $\frac{19}{3}-x$ & 7 \\
\hline 9. & Zhithe & $1054-1055$ & 至 死 & 1 \\
\hline 10 . & Jiayou & $1054-1055$ & Fe bet. & 10 \\
\hline 11. & Zhiping & $1064-1067$ & 济乍 & 7 \\
\hline 12. & xinlng & $2068-1077$ & 昖 类 & 27 \\
\hline 13. & Yuanfeng & $1078-1085$ & 3 , 五 & 68 \\
\hline 14. & Yuanyou & $1086-1094$ & 元 功 & 48 \\
\hline 15 . & Shaosheng & $1094-1097$ & 点占 咀 & 21 \\
\hline 16. & Daguan & $1107-1110$ & 工萡得 & 1 \\
\hline 17. & Zhenghe & $1111-1117$ & 政 & 24 \\
\hline 18. & Yine & $1119-1125$ & 直 大乙 & 1 \\
\hline \multicolumn{2}{|c|}{ MATA UANG JEPANG } & & & 1 \\
\hline 1. & Daght & $1126-1131$ & 士 초․ & 1 \\
\hline
\end{tabular}




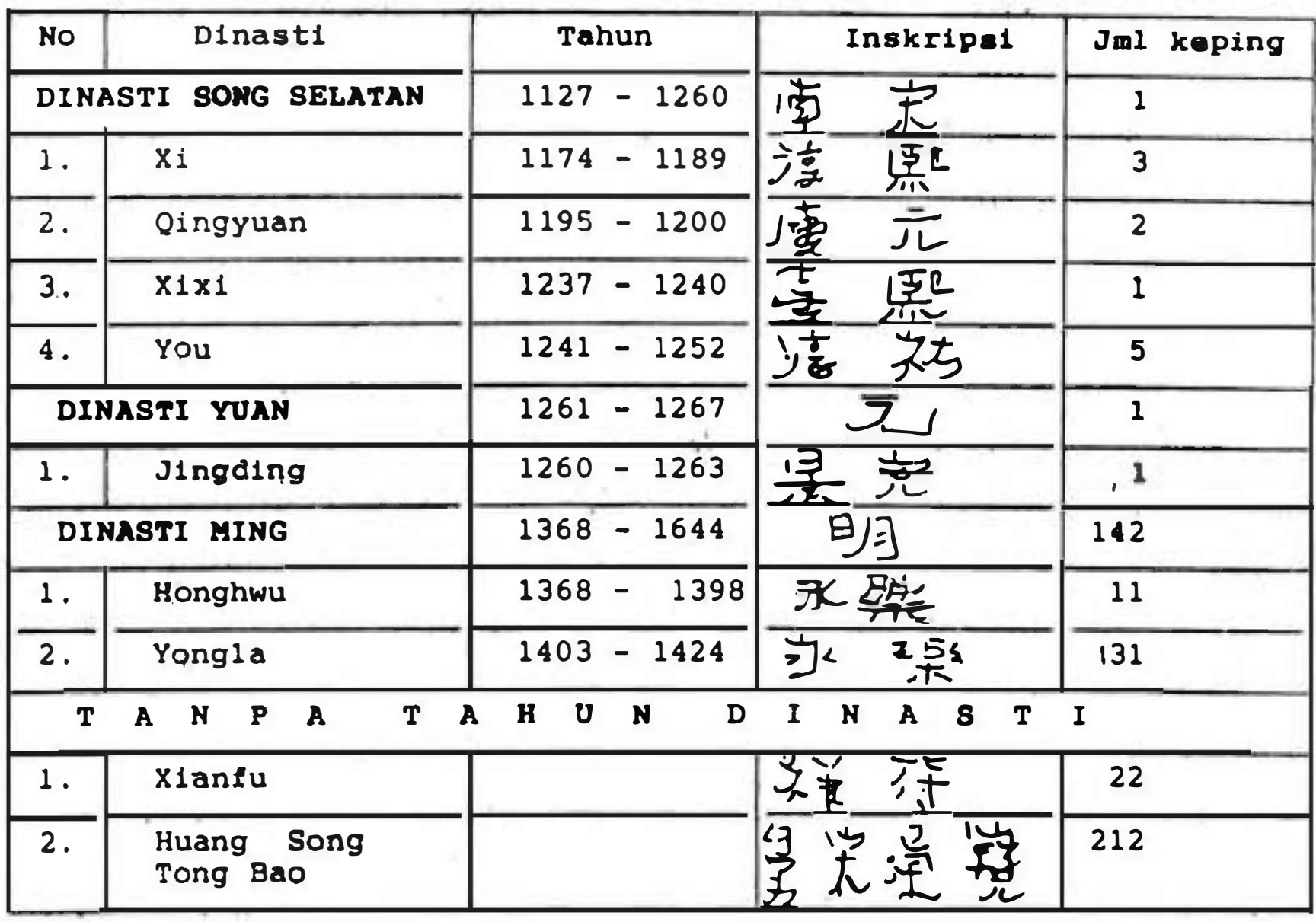


TEMUAN MATA UANG DK. MGguplak, DS. GONDOSARI, KEC. GEBOG, KAB. KUdUS

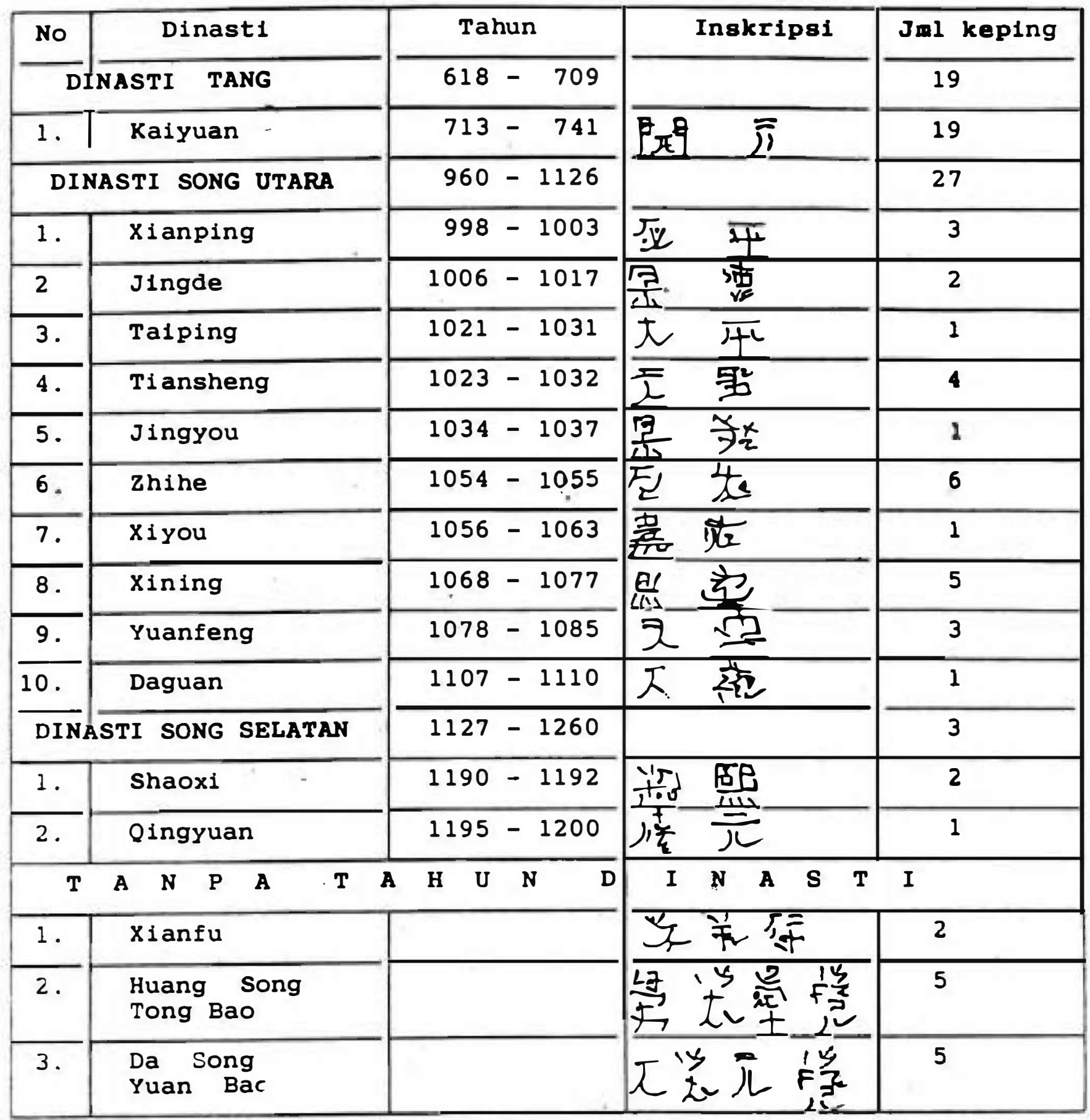




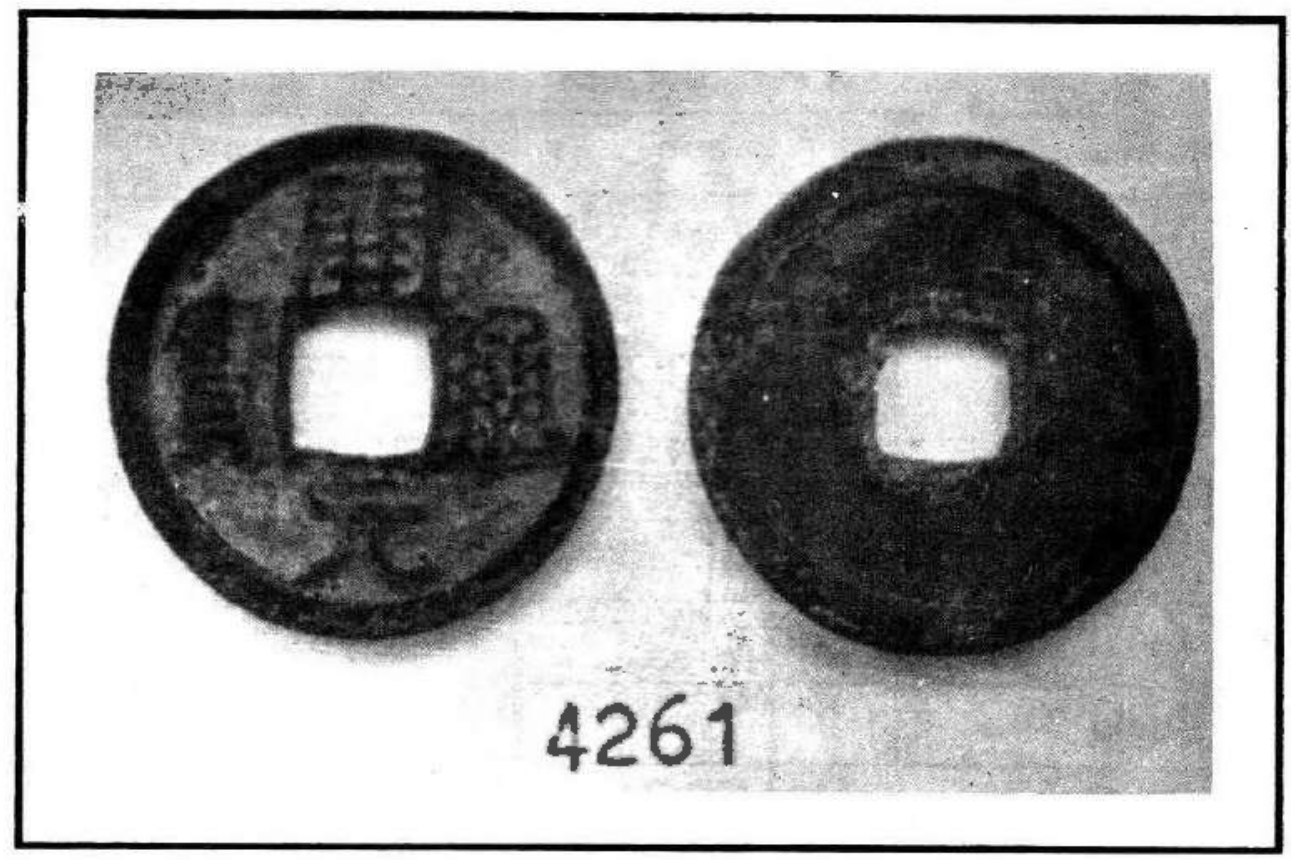

Mata Uang dari Dinasti Tang

Kaisar Kaiyuan (713 - 741 M)

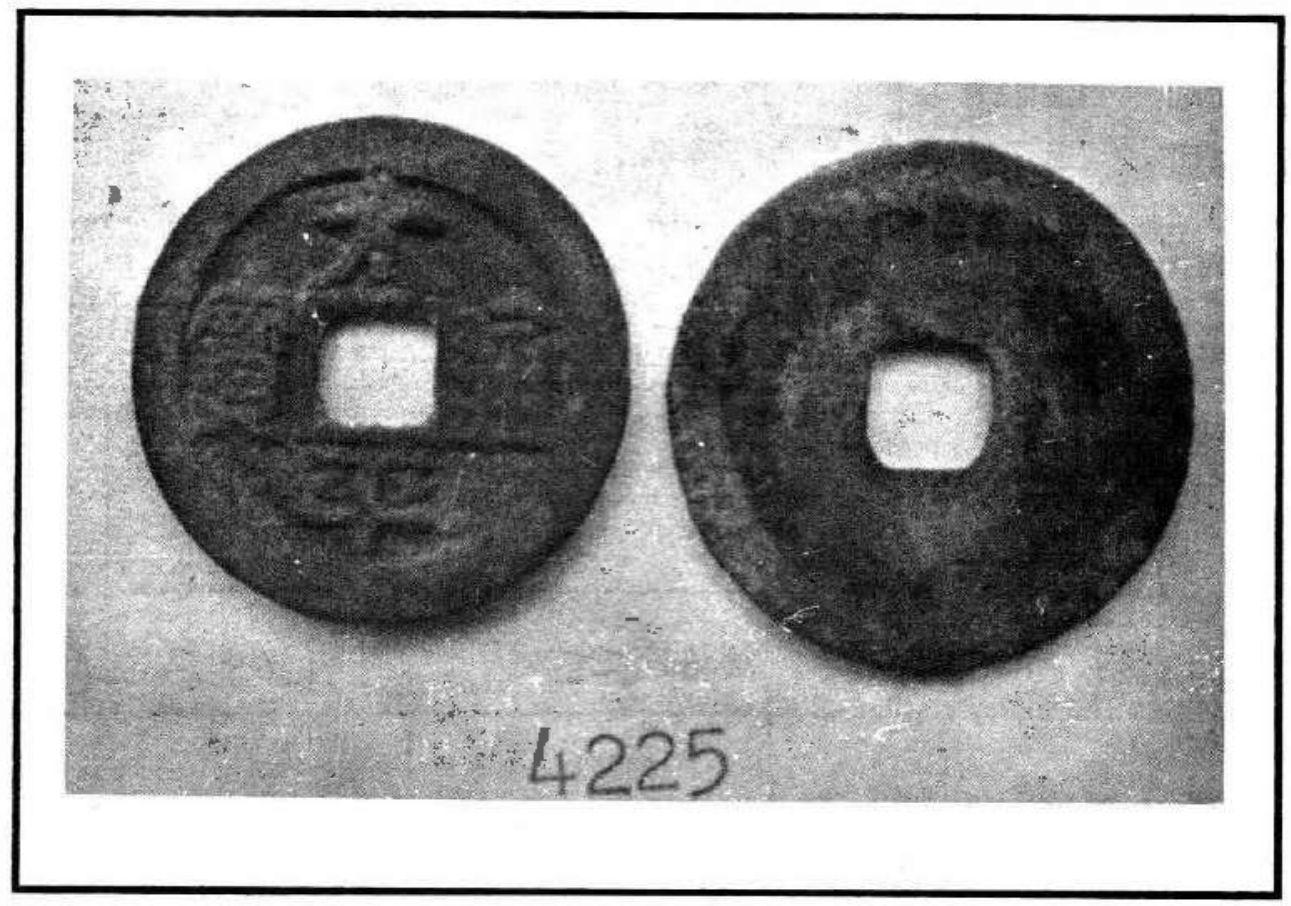

Mata Uang Jepang

Kaisar Daghi (1126 - 1131 M) 


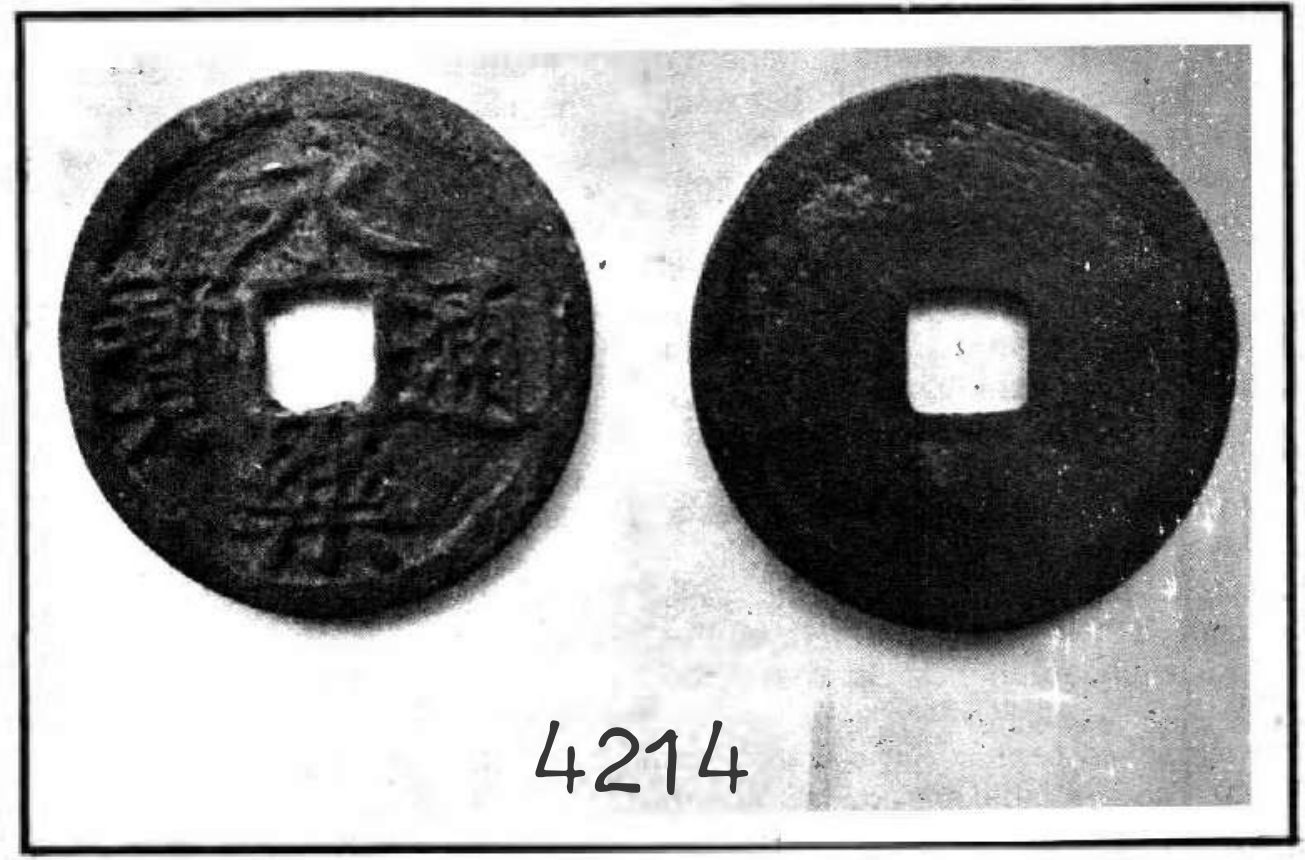

Mata Uang dari Dinasti Ming Kaisar Honghwe (1368 - $1398 \mathrm{M})$ 